\title{
Overview
}


This chapter presents the key findings of the 2010 Living Costs and Food Survey (LCF), formerly the Expenditure and Food Survey. The chapter provides an overview of household income and expenditure, characterised by different household types and regions, as well as a summary of the ownership of a limited range of durable goods.

All of the tables (except Table 1.1) referred to in this chapter can be found in Appendix $A$ of the report (page 125).

\section{Household expenditure}

Table 1.1 shows total weekly household expenditure in the United Kingdom (UK) by the 12 Classification Of Individual COnsumption by Purpose (COICOP)' categories. In 2010 average weekly household expenditure in the UK was $£ 473.60, £ 18.60$ more than in 2009 when it was $£ 455.00$, reversing the change seen in the previous year. As in previous years, spending was highest on transport at $£ 64.90$ per week. This was $£ 6.50$ more than in 2009 , a large increase of 11 per cent.

Housing, fuel and power (£60.40) and recreation and culture (£58.10) were the categories with the next highest expenditure. Housing, fuel and power saw an increase of $£ 3.10$ making it the second highest category, now higher than recreation and culture which saw only a small increase of 20p. The average weekly expenditure on food and non-alcoholic drinks in 2010 was $£ 53.20$ per week.

\section{Table 1.1 Expenditure by COICOP category and total household expenditure, 2010 United Kingdom}

\begin{tabular}{lr}
\hline COICOP category & $£$ per week \\
\hline Transport 64. & 90 \\
Housing, fuel and power & 60.40 \\
Recreation and culture & 58.10 \\
Food and non-alcoholic drinks & 53.20 \\
Restaurants and hotels & 39.20 \\
Miscellaneous goods and services & 35.90 \\
Household goods and services & 31.40 \\
Clothing and footwear & 23.40 \\
Communication & 13.00 \\
Alcoholic drinks, tobacco and narcotics & 11.80 \\
Education & 10.00 \\
Health & 5.00 \\
\hline Total COICOP expenditure & 406.30 \\
\hline Other expenditure items & 67.30 \\
\hline Total expenditure & 473.60 \\
\hline
\end{tabular}

Totals may not add up due to independent rounding of component categories. 
Of the $£ 64.90$ spent on transport each week, approximately half (49 per cent) was spent on the operation of personal transport (£33.30), see Table A1. This was an increase of 14 per cent on the previous year, in line with the overall increase observed in spending on transport. As in 2009 petrol, diesel and other motor oils ( $£ 21.60$ per week) was the largest expenditure in the operation of personal transport category, an increase from $£ 19.20$ in 2009. Households spent on average $£ 12.10$ per week on transport services, including rail, tube and bus fares, compared to $£ 9.60$ in 2009, however the purchase of vehicles, remained the same at $£ 19.50$ per week in 2010.

Approximately a third (31 per cent) of spending on recreation and culture ( $£ 17.80$ per week) was spent on recreational and cultural services: sports admissions, leisure class fees and equipment hire accounted for $£ 5.30$ per week; cinema, theatre and museums etc ( $£ 2.40$ per week); TV, video, satellite rental, cable subscriptions and TV licenses ( $£ 6.00$ per week); and gambling payments (£2.70 per week).

Average weekly spend on package holidays fell from $£ 13.20$ per week in 2009 to $£ 12.60$ in 2010 . Of this, $£ 11.60$ was spent on holidays abroad, £0.70 less than in 2009. Spending on audio-visual, photographic and information processing equipment ( $£ 7.20$ per week) remained relatively constant, while spending on other recreational items and equipment, gardens and pets increased to $£ 11.40$ per week. The average weekly spend on TV, video and computers increased to £5.20. (Table A1).

Of the $£ 53.20$ average weekly spend on food and non-alcoholic drinks , $£ 7.10$ was spent on fresh fruit and vegetables; $£ 3.10$ on fruit and $£ 4.00$ on vegetables; $£ 11.60$ was spent on meat, the highest proportion (48 per cent) of which was spent on other meat and meat preparations (£5.60 per week); $£ 5.00$ was spent on bread, rice and cereals; $£ 3.20$ was spent on buns, cakes, biscuits, etc; and £4.30 was spent on non-alcoholic drinks (Table A1). 81 per cent, £43.10 per week of food and non-alcoholic drinks were purchased from large supermarket chains (Table A2), an increase of $£ 5.40$ on the previous year.

\section{Household expenditure by income}

Household incomes have been ranked in ascending order and divided into decile groups in order to examine expenditure patterns between different income groups. Households with the smallest income lie in the first decile group and those with the largest income lie in the top decile group. Average weekly household expenditure in 2010 ranged from $£ 185.60$ in the lowest of the 10 income decile groups to $£ 1,018.50$ in the highest (Figure 1.1, Table A4); expenditure in this highest decile was $£ 26.40$ higher than in 2009 , reversing the drop seen in the previous year. 


\section{Figure 1.1 Household expenditure by gross income decile group, 2010 United Kingdom}

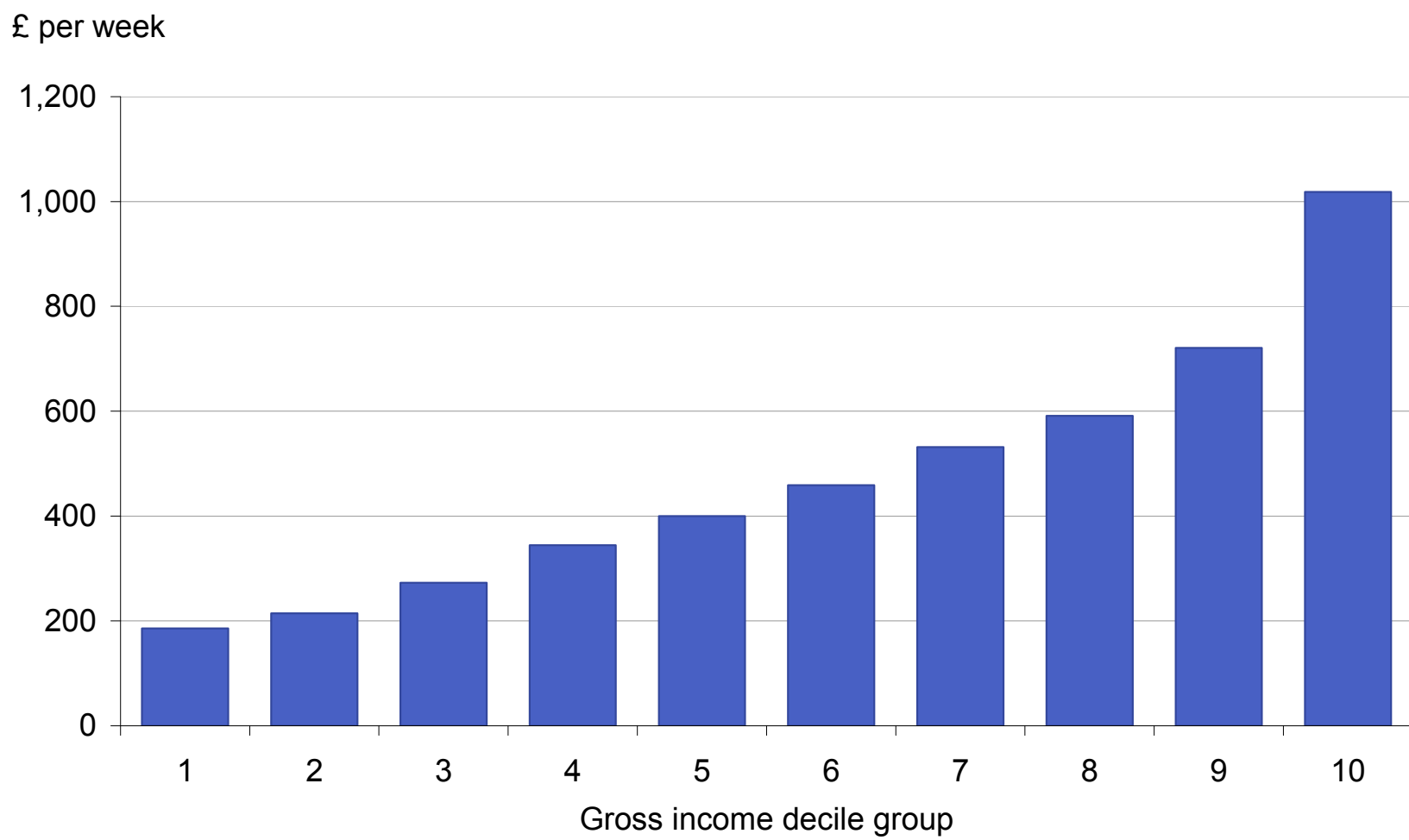

Households in the lowest income decile group spent a larger proportion of their total average weekly expenditure on housing, fuel and power (23 per cent), and food and non-alcoholic drinks (15 per cent), than those in the highest income decile group (8 per cent in both expenditure categories). However, households in the highest income decile group spent a greater proportion on transport (15 per cent) and recreation and culture (13 per cent) than those in the lowest income decile group ( 9 and 10 per cent respectively) (Table A5).

\section{Household expenditure by age}

Average weekly expenditure varied with the age of the household reference person (HRP). As in 2009, households whose HRP was aged 30 to 49 years had the highest average expenditure (£573.10 per week) while those with an HRP aged 75 years and over had the lowest average household expenditure ( $£ 240.40$ per week). It should be noted that households with an HRP aged 30 to 49 years contained an average of 3 people, whereas households with an HRP aged 75 years and over contained an average of 1.4 people (Table A9).

Spending on housing, fuel and power in households whose HRP was aged less than 30 years fell from $£ 97.30$ in 2009 to $£ 91.70$, a drop of 6 per cent (Table A9). This compares with 20 per cent of total household expenditure for households with a HRP aged less than 30 , whereas households with an HRP aged 75 years or over spent 18 per cent of their total household expenditure on housing, fuel and power (Table A10). 
The proportion of expenditure spent on food and non-alcoholic drinks increased with age, from 9 per cent among households with an HRP aged less than 30 years to 16 per cent among households with an HRP aged 75 years and over.

The pattern of spending on restaurants and hotels, as a proportion of total expenditure, was relatively constant among age groups, with the percentage of total expenditure ranging from 9 per cent among households with an HRP aged less than 65, to 6 per cent among households with an HRP aged 75 years and over (Table A10). When the amount spent is considered, household expenditure on restaurants and hotels was greatest in households with an HRP aged between 30 and 49 ( $£ 49.10$ per week), but much lower in households with HRP over 75 ( 14.10 per week). This compares with an average expenditure across all ages of $£ 39.20$ (Table A11).

Expenditure on recreation and culture, as a proportion of total spending, increased from 9 per cent among households with an HRP aged less than 30 years to a maximum of 15 per cent among households with an HRP aged 65 to 74 years (Table A10).

\section{Figure 1.2 Expenditure on selected items as a proportion of total spending by age of the HRP, 2010 United Kingdom}

Per cent

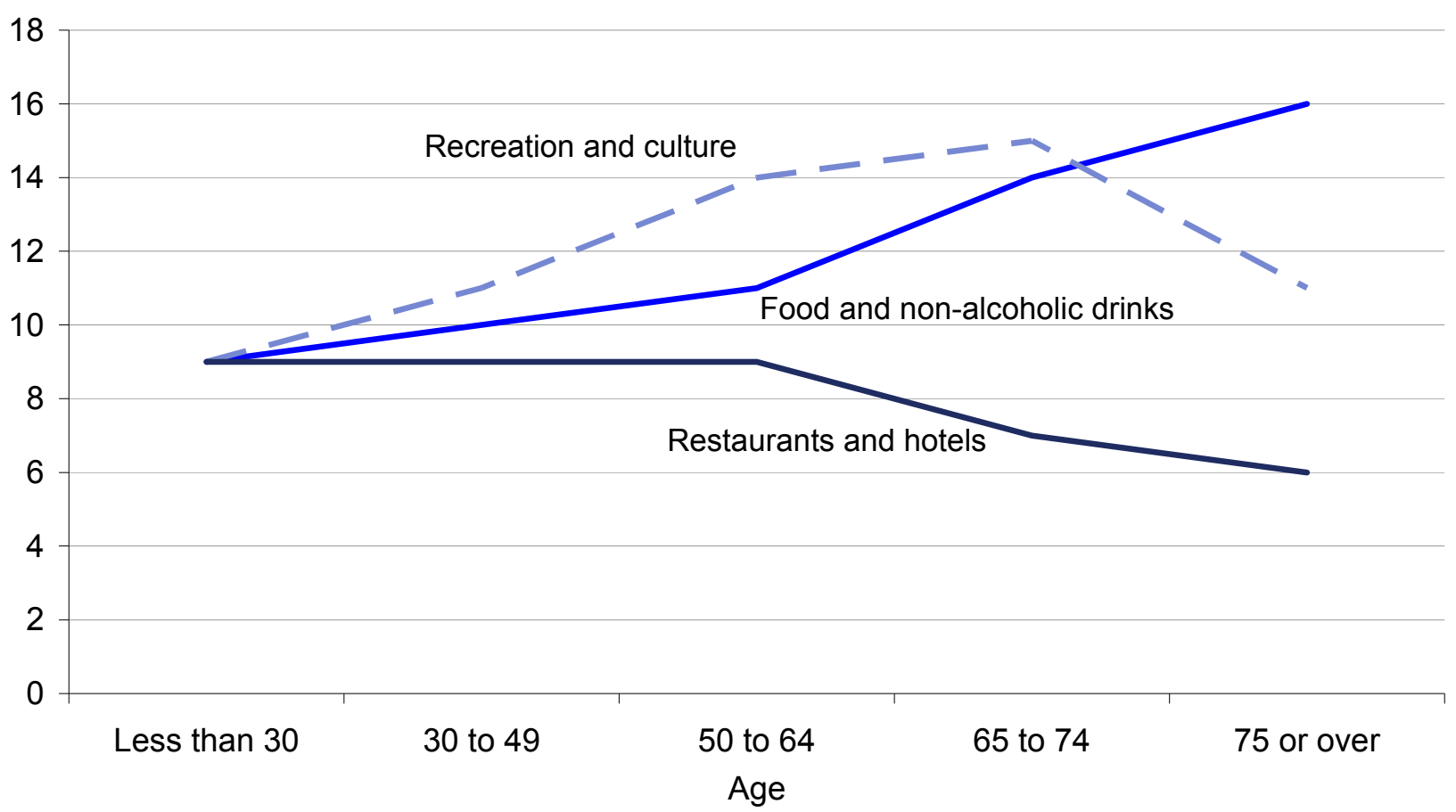




\section{Household expenditure by economic activity and socio-economic classification}

This analysis uses the National Statistics Socio-Economic Classification (NS-SEC), see Appendix B, page 222 .

Household spending varied with the economic status of the HRP. The average weekly expenditure of households where the HRP was in employment ( $£ 587.20$ per week) was just under twice that of households where the HRP was unemployed ( $£ 309.60$ per week), and of households where the HRP was economically inactive (£309.50 per week) (Table A17).

In households where the HRP was in employment, spending was greatest on transport (£84.80 per week) and recreation and culture ( $£ 69.90$ per week). Among households where the HRP was unemployed, spending on housing, fuel and power was greatest ( $£ 54.50$ per week), followed by transport (£47.40 per week) (Table A17).

Average weekly expenditure was highest among households where the HRP was in the 'large employers and higher managerial' occupational group, at £856.10 per week. An average weekly expenditure of $£ 418.10$ was recorded for households where the HRP was in a 'routine' occupation (Table A22).

\section{Household expenditure by household composition}

Generally, household expenditure increased with the size of the household. Thus, average weekly household expenditure was lowest among retired one-person households who were mainly dependent on the state pension (£161.10) and highest among households containing three or more adults with children (£747.30) (Table A23).

\section{Household expenditure by region}

Overall, average household expenditure in the UK was $£ 466.50$ per week for the years 2008-10 combined. There were five regions in which expenditure over this period was higher than the UK average: expenditure was highest in London (£577.80), followed by the South East (£523.20 per week), the East (£493.40), the South West (£482.60) and Northern Ireland (£482.80). Spending was lowest among households in the North East (£372.70), Wales (£394.00), and Yorkshire and the Humber (£405.50) (Figure 1.3, Table A33). 


\section{Figure 1.3 Household expenditure by region, 2008 to 2010 United Kingdom}

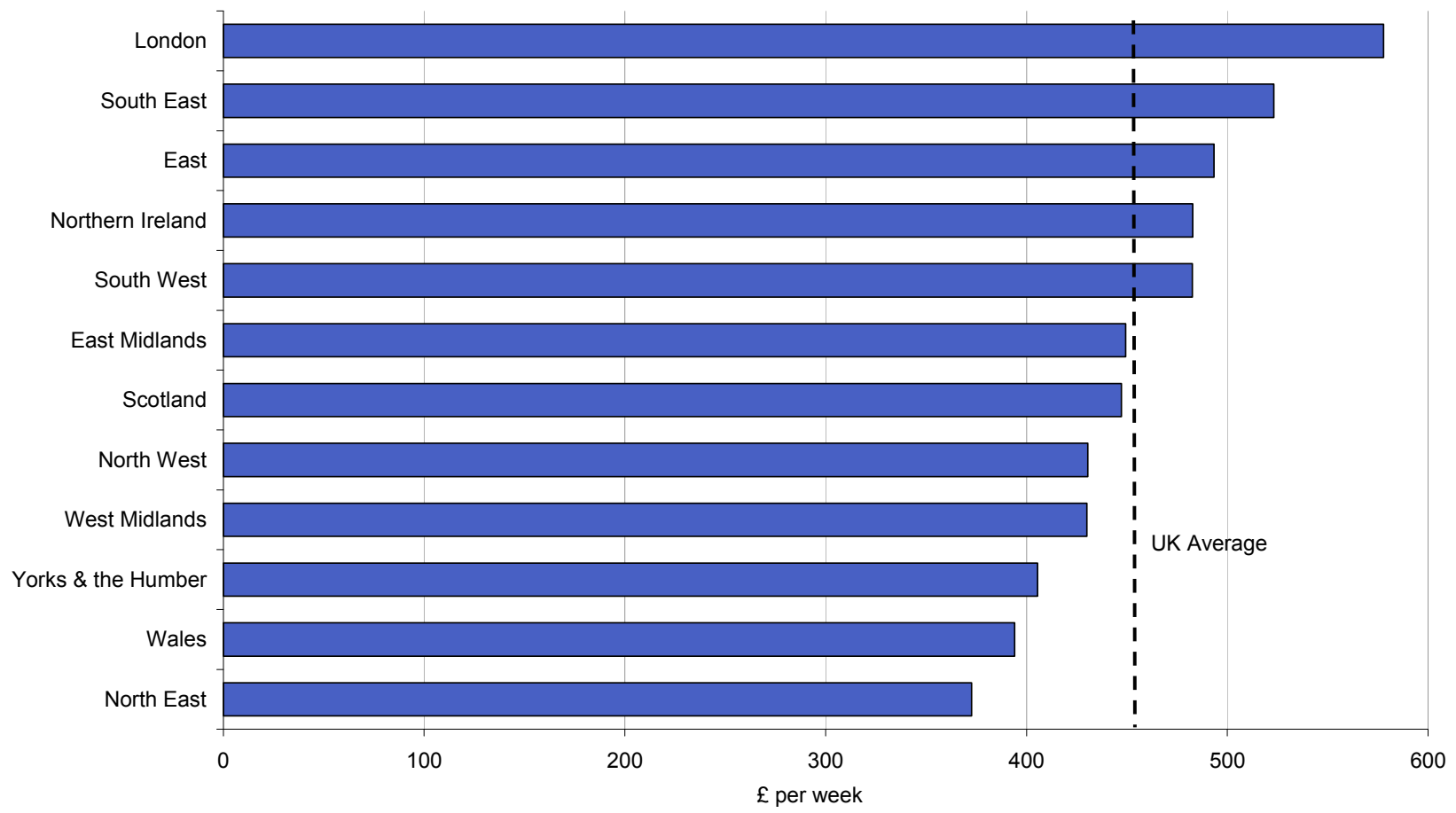

During the three-year period, 2008-2010, spending on transport was highest among households in the South East ( $£ 73.50$ per week) and lowest among those in the North East ( $£ 49.10$ per week). Households in London spent the most on housing, fuel and power ( $£ 87.00$ per week) compared with the UK national average of $£ 56.90$ per week (Table A35). Housing expenditure is looked at in more detail in chapter two.

Households in rural areas had higher overall expenditure ( $£ 506.30$ per week) than those in urban areas ( $£ 454.60$ per week). This was reflected in expenditure on transport, where spending was highest ( $£ 76.00$ in rural areas and $£ 58.30$ in urban areas), and recreation and culture ( $£ 68.00$ in rural areas and $£ 55.80$ in urban areas). However, expenditure on housing, fuel and power was slightly higher in urban areas ( $£ 58.00$ per week) than in rural areas ( $£ 54.50$ per week) (Table A36).

\section{Household income}

Income is defined within the survey as the gross weekly cash income current at the time of interview. Income includes salaries and wages, income from self employment, benefits and pensions. See Appendix B for further details on income.

Average gross weekly household income in the UK in 2010 was $£ 700.00, £ 17.00$ more than in 2009 ( $£ 683.00$ per week). Besides wages and salaries (65 per cent), social security benefits formed the largest proportion of income (14 per cent), followed by self-employment income (10 per cent), and income from annuities and pensions (8 per cent) (Figure 1.4, Table A37). 


\section{Figure 1.4 Percentage of gross weekly household income by source of income, 2010 \\ United Kingdom}

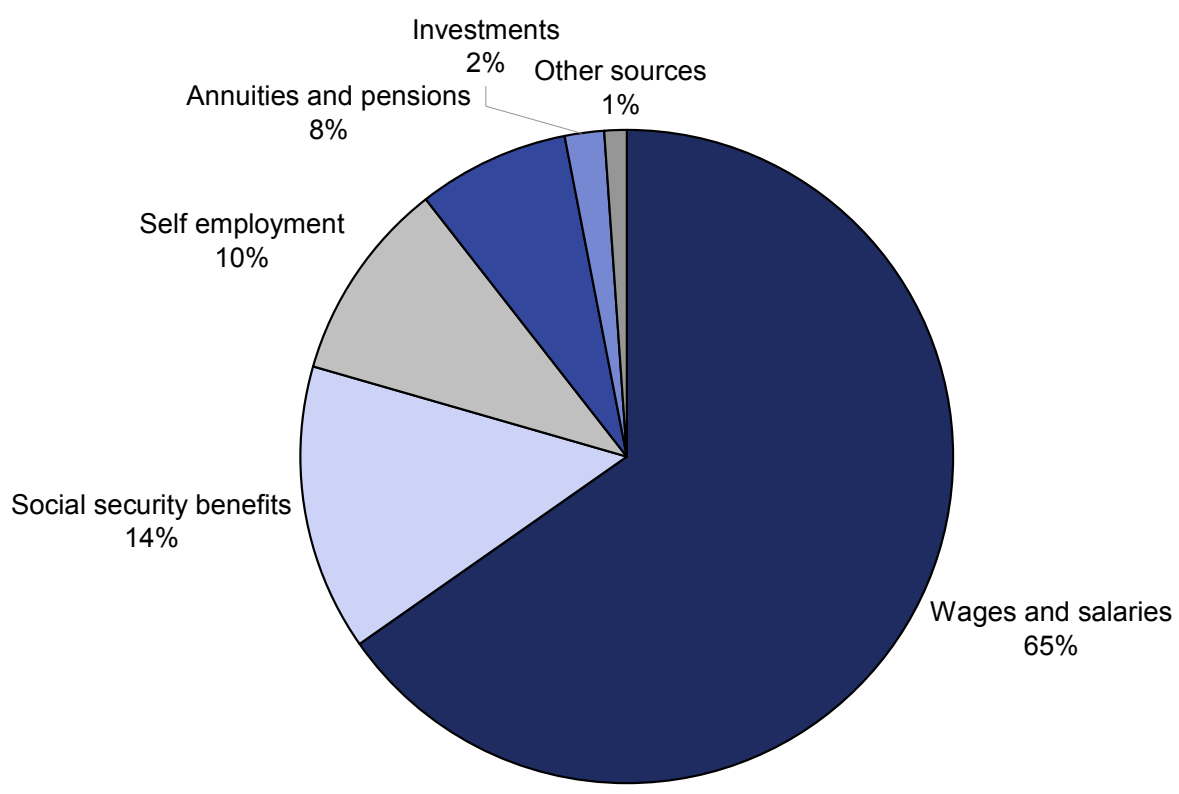

\section{Household income by age}

Households with an HRP aged 30 to 49 recorded the highest gross weekly income at $£ 894$ per week. Of this, 80 per cent was acquired from wages and salaries. The lowest gross weekly income was recorded by households with an HRP aged 75 years or over ( $£ 350$, an increase of $£ 19.00$ from the previous year) with 52 per cent of their income gained through social security benefits.

Households with a household reference person (HRP) aged less than 65 years of age had a higher average weekly gross income than those with an HRP aged 65 years and over. However, the older age groups had a higher proportion of disposable income: 92 per cent for households with an HRP aged 65 to 74 years and 93 per cent for households with an HRP aged 75 years or over. This compares with households with an HRP aged 30-49, where 80 per cent of income was disposable (Table A38).

\section{Household income by region}

There were three English regions that exceeded the 2008-2010 UK national average income of $£ 699$. They were London (£982), the South East (£810) and the East (£749). Income was lowest among households in the North East (£543 per week) and Yorkshire and the Humber ( 5570 per week).

Among UK countries, households in England had the highest average gross weekly income (£711), whereas those in Wales had the lowest average income at $£ 604$ per week (Table A41). 


\section{Household income by economic activity and socio-economic classification}

Households where the HRP was in the 'large employers and higher managerial' occupational group had an average gross weekly income of $£ 1,653$, almost three times the income of households where the HRP worked in a 'routine' occupation (£612). Incomes for these occupational groups were acquired mainly from wages and salaries (92 and 84 per cent respectively).

Households with an HRP in the 'large employers and higher managerial' occupational group also received the highest proportion of their average gross weekly income $(£ 1,653)$ from wages and salaries (92 per cent). By contrast, those households with an HRP in the 'long-term unemployed' occupational group obtained 75 per cent of their average gross weekly income (£258) from social security benefits (Table A43).

\section{Ownership of durable goods}

Overall, 77 per cent of households had a home computer and 73 per cent had an internet connection at home, an increase of 2 percentage points for both from 2009 (Table A45). Among households in the highest income decile 98 per cent had a home computer and 97 per cent an internet connection, compared with only 46 and 39 per cent of households in the lowest income decile. This does, however, represent an 8 percentage point increase in households with a home computer and a 6 percentage point increase on households with an internet connection in the lowest income decile from 2009 continuing the upward trend (Table A46).

In general, households with children were more likely to have an internet connection than those without. Overall, 92 per cent of two-adult, non-retired households owned a home computer, with 89 per cent having an internet connection (Table A46).

Connection to the internet was lowest among households in Northern Ireland (61 per cent) and the North East (64 per cent) and highest in the London (77 per cent). Ownership of a mobile phone was lowest among households in Wales (48 per cent) and highest in the East Midlands at 86 per cent (Table A48).

Three-quarters (75 per cent) of all households owned a car or van, with 30 per cent owning two or more. Ownership of at least one car or van varied from 32 per cent in the lowest income decile, to 96 per cent in the ninth decile (Table A47).

Ownership of a car or van was highest among households in the South West (83 per cent), the East (82 per cent) and the South East (81 per cent), and lowest among households in London (65 per cent) and the North East (68 per cent) (Table A48).

1 From 2001-02, the Classification Of Individual COnsumption by Purpose (COICOP) was introduced as a new coding frame for expenditure items. COICOP is the internationally agreed classification system for reporting household consumption expenditure. Total expenditure is made up from the total of the COICOP expenditure groups (1 to 12) plus 'Other expenditure items (13)'. Other expenditure items are those items excluded from the narrower COICOP classifications, such as mortgage interest payments, council tax, domestic rates, holiday spending, cash gifts and charitable donations. 